\title{
O GOSTO E O CHEIRO: PRÁTICAS DE CONSUMO E DIFERENÇAS REGIONAIS NO BRASIL
}

\author{
Salete NERY*
}

RESUMO: O objetivo deste artigo é compreender o gosto do brasileiro pelo perfume. O Brasil é o segundo maior consumidor mundial de perfumes. Os produtos mais consumidos são os nacionais e massivos. Os maiores consumidores são pessoas das Classes C, D e E das regiões Norte e Nordeste, que, segundo dados do Instituto Brasileiro de Geografia e Estatística (IBGE) (2010), gastam familiarmente por mês mais com perfumes do que com arroz ou com educação. O ponto de partida é o debate sobre o suposto caráter supérfluo dos perfumes, à luz da particularidade sócio-histórica do Brasil. Daí buscamos compreender esse gosto a partir da relação daquilo que foi considerado pela pesquisadora Renata Aschcar como o cheiro do Brasil no século XX, a lavanda, a partir de um de seus produtos de destaque na história nacional da perfumaria: a Seiva de Alfazema criada pela Phebo.

PALAVRAS-CHAVE: Gosto. Consumo. Perfumes. Brasil.

\section{Introdução}

O vídeo-documentário Vaidade (2003), dirigido por Fabiano Maciel, ganhador do prêmio de Melhor Documentário na Mostra do Filme Etnográfico em 2005 (Rio de Janeiro), e ambientado em cidades do Pará, estado da região Norte do Brasil, parece ter como uma de suas motivações principais um estranhamento: Como entender a relação do paraense com os cheiros? Na tela visualizamos grupos empobrecidos, em cidades remotas e pequenas do país, que chegam a trocar o

\footnotetext{
UFRB - Universidade Federal do Recôncavo da Bahia. Centro de Artes, Humanidades e Letras. Cachoeira - BA - Brasil. 44300000 - saletenery@uol.com.br. http://orcid.org/0000-0002-7723-2243.
} 
ouro obtido no garimpo ou mesmo peixe, na falta de outros recursos, por perfumes comercializados por grandes empresas de perfumaria nacionais ou estrangeiras uma região do país cujas famílias economicamente menos favorecidas, a exemplo do que também ocorre na região Nordeste, gastam mais mensalmente com perfumes do que com ítens de educação, que envolvem variados produtos, desde escola e livros a material escolar, segundo dados do Instituto Brasisleiro de Geografia e Estatística (IBGE) (BRASIL, 2010). Através do documentário, temos contato com pessoas que têm quatro ou mais perfumes em suas prateleiras, o que nos leva ao questionamento sobre: o que motiva pessoas a investirem, mensalmente, mais em perfumes do que em arroz pelos dados apresentados na Pesquisa de Orçamentos Familiares (BRASIL, 2010), do IBGE? Por que/Como perfumes poderiam ter angariado tamanha importância nos gostos de nortistas e nordestinos do país?

Quando tratamos do Norte e Nordeste do Brasil, estamos apontando duas regiões de baixo Produto Interno Bruto (PIB) no país: respectivamente, cada uma delas corresponde a 5,4\% e 14,3\%, em confronto com as regiões Sudeste $(53,2 \%)$, Sul (17\%) e Centro-Oeste (10\%), conforme as estatísticas apresentadas pelas Contas Regionais do Brasil 2010-2016 (BRASIL, 2016). Ainda assim, são as regiões que, a partir de seu consumo de perfumes massivos pelas classes C, D e E, têm importância capital para o lugar ocupado pelo país no ranking internacional de consumo de perfumes. Hoje, o Brasil está em segundo lugar quanto ao consumo de perfumes para uso pessoal no mundo, tendo movimentado $\mathrm{R} \$ 23$ bilhões em 2017, crescimento de $11,7 \%$ em relação ao ano anterior, de acordo com dados apresentados no Caderno de Tendências 2019-2020, produzido pela Associação Brasileira da Insdústria de Higiene Pessoal, Perfumeria e Cosméticos (ABIHPEC) em parceria com o Serviço Brasileiro de Apoio às Micro e Pequenas Empresas (SEBRAE). "Segundo dados da Euromonitor International, enquanto no mundo a categoria [perfumaria] representa 11\% do total de HPPC [produtos de higiene pessoal, perfumaria e cosméticos], no Brasil representa 23\%. Isso mostra o quanto os perfumes fazem parte da rotina de cada brasileiro" (ABIHPEC; SEBRAE, 2018, p.53). No entanto, fazem parte muito diferencialmente, pois, conforme dados do Kantar Worldpanel, apresentados no mesmo caderno de tendências, a penetração dos perfumes, que é de aproximadamente $60 \%$ no Brasil, sobe para o expressivo número de quase $80 \%$ nas regiões Norte e Nordeste, enquanto na região Sul seria de $45 \%$. Ou seja, nas regiões Norte e Nordeste, a cada 10 pessoas, aproximadamente oito (8) consomem perfumes.

No curto período de maior desenvolvimento do Brasil, quando o PIB da região Nordeste chegou a crescer mais do que a média nacional, esta região foi considerada a grande responsável para o fato de, entre 2010 e 2014, o Brasil ter alçado à condição de maior consumidor nacional de fragrâncias para uso pessoal - ultrapassando os Estados Unidos, país mais rico e populoso -, mesmo às custas de um consumo, 
por excelência, de nordestinos dos estratos socioeconômicas menos privilegiados, a partir de produtos nacionais e massivos. As fragrâncias mais consumidas são as Águas, quase metade do consumo, e as Colônias que incluem as deocolônias e os deoperfumes, que representam a outra metade. Tratam-se de perfumes com menor concentração de fragrâncias: em torno de 5 e 10\% (no caso da categoria parfum, a concentração pode ultrapassar os 30\%). Com menor teor de fragrância e de fixadores, as Águas e as Colônias são os produtos mais baratos para perfumação pessoal e que volatilizam mais rapidamente. No Brasil, cerca de $90 \%$ dos produtos vendidos são nacionais. Destaque-se que, juntas, as empresas brasileiras Boticário e Natura representam mais de 50\% desse mercado. Além disso, a fragrância é item decisivo na escolha de uma variedade de outros produtos no país, como cosméticos e mesmo produtos de limpeza da casa (ABIHPEC, 2018a).

Em suma, mesmo em contexto de crise político-econômica, o Brasil, apesar dos abalos sofridos pelo setor nacional de perfumaria, permaneceu em lugar de destaque quanto ao consumo de fragrâncias para uso pessoal $\left(2^{\circ}\right.$ lugar no período de 2015 a 2018) consumindo, destacadamente, produtos mais baratos sendo que os nortistas e, especialmente, os nordestinos de menor renda têm importante papel nesse resultado. Dois fatores normalmente são acionados na tentativa de explicar o panorama: o tamanho das regiões e o clima mais quente. No que se refere ao tamanho, o que importa é o índice populacional, e não a área geográfica e nesse quesito, o Sudeste é a região de maior PIB e mais populosa. Por sua vez, no que se refere ao clima e à associação da perfumação aos banhos, tomados em maior quantidade ao longo do dia, a compensação estaria no preço dos produtos consumidos. Consome-se mais fragrâncias ao longo do dia, mas, por isso mesmo, elas podem ser as mais baratas splash (de menor fixação). Ou seja, a compreensão do gosto pelo perfumar-se das camadas menos aquinhoadas do país de regiões de menor PIB não passa por uma possível lógica da imitação como vetor interpretativo basilar. A região Sudeste poderia suplantar esse consumo em volume e em valor monetário desprendido por ser uma região simultaneamente mais rica e mais populosa do que a Nordeste, principal mercado nacional das fragrâncias de massa. No entanto, isso não ocorre devido a diferenças de fundo sócio-histórico. E é essa especificidade histórica, que teve por consequência relações singulares com o perfume, que tem levado à aposta na rápida recuperação do mercado de perfumaria no país, o que começa a ocorrer. O brasileiro, afirma-se, poderia diminuir o consumo de fragrâncias para uso pessoal, mas não cortaria o referido item de sua cesta de compras: "O brasileiro vai continuar usando perfume - e muito!” (ABIHPEC, SEBRAE, 2018, p.55). O objetivo deste artigo é, portanto, compreender o gosto do brasileiro por perfumes para uso pessoal. 


\section{Supérfluo?}

O estranhamento causado pelos números referentes ao consumo de perfumes no Brasil se dá inicialmente devido à suposta superfluidade do produto em questão. Por isso, inclusive, a comparação entre consumo de perfumes e consumo de ítens como educação e arroz faz sentido no aguçamento dessa perplexidade para exposição da problematização que torna pertinente a pesquisa. No entanto, como afirmei em outro artigo (NERY, 2017), em lugar de arriscarmos grosseiramente a interpretação de que pessoas com menor poder aquisitivo valorizam mais o supérfluo do que ítens de necessidade, buscamos compreender o modo de interpretação a respeito dos perfumes na relação com a vida dos nordestinos a partir de uma série de técnicas de investigação que envolveram questionários, entrevistas em profundidade e mesmo um teste aromático, aplicados nos anos de 2014 e 2015, nas ruas da cidade de Cachoeira-BA, a $110 \mathrm{~km}$ da cidade de Salvador, capital da Bahia. A referida cidade foi escolhida devido a ser contígua espacial e culturalmente à capital, centro irradiador privilegiado de modos de vida para todo o estado, e ter renda média de classe C, de acordo com os dados do IBGE (2010). Ainda que o referido órgão não opere a partir de recorte de classe, foi necessário proceder o ajuste analítico devido aos dados dos relatórios sobre consumo de perfumes no Brasil apresentarem as estatísticas a partir desse recorte utilizando a classificação da Associação Brasileira das Empresas de Pesquisa (ABEP). Assim, a cidade de Cachoeira-BA se apresentou como um microcosmo que poderia contribuir para o surgimento de hipóteses interpretativas à compreensão da relação dos baianos e nordestinos com o perfume, apesar da evidente diversidade que marca o estado e, mais particularmente, a região.

$\mathrm{Na}$ aplicação dos questionários-piloto, no entanto, um problema surgiu, e ele se mostrou definidor dos rumos da investigação. Inicialmente utilizamos informações publicadas a respeito de uma pesquisa realizada sobre consumo de perfumes no Brasil que apontava que o elemento motivador primeiro para o consumo de perfumes era a sedução, depois viriam a evidência de poder e, por fim, bem-estar (SANTOMAURO, 2011). Contudo, em nossa pesquisa-piloto, percebemos outra resposta de grande incidência: "uso porque gosto". Esta recorrente frase, que pode englobar o bem-estar, o poder e a sedução, parecia trazer elementos adicionais a uma incursão interpretativa acerca da participação dos perfumes na rotina de seus usuários.

Com a aplicação dos questionários finais, percebemos que pessoas que ganhavam, à época, até um salário mínimo individualmente, costumavam ter até mais do que quatro (4) perfumes em suas prateleiras domésticas, com aquisição bimensal de novos produtos. Entre as setenta (70) mulheres entrevistadas, Vinte e oito (28) afirmaram ter quatro (4) ou mais perfumes em casa no momento da entrevista, sendo que metade delas ganhava um salário mínimo e a outra metade 
menos do que um salário mínimo. Vinte e uma (21) respondentes afirmaram ter três (3) perfumes, sendo que dezessete (17) delas recebia menos do que um salário mínimo. Apenas quatro (4) dentre as setenta (70) entrevistadas afirmaram não usar perfume e, mesmo assim, duas delas afirmaram ter o produto em casa.

No caso dos homens, de um total de sessenta e seis (66) entrevistados, três (3) afirmaram não usar perfume. A maioria deles, vinte e cinco (25), afirmou ter dois perfumes em casa no momento da entrevista, sendo que, destes, dezessete (17) tinham renda abaixo de um salário mínimo. Tomamos, para entrevista, moradores permanentes da zona urbana da cidade a partir de uma amostra estratificada por sexo. O recorte se limitou à faixa etária entre 20 e 49 anos. A aplicação do questionário ocorreu em diferentes dias da semana, horários e pontos da cidade.

Ou seja, tratavam-se de pessoas em idade produtiva, com baixo rendimento, e, ainda assim, com prateleira diversificada de produtos, adquiridos, por excelência, via catálogos - a cidade contém apenas uma loja física de perfumaria (Boticário), tendo como demais opções de compra direta mercados e farmácias. O que significa, no entanto, afirmar que se usa o produto por gosto? As entrevistas em profundidade ajudaram a perceber que a relação estabelecida com o produto vem muito precocemente. Desde o nascimento, as mães aromatizam as crianças e seguem com esse ritual diário ao longo de seu desenvolvimento, o que se prolonga em suas vidas adultas. De acordo com Bourdieu (2007), o gosto popular pode ser primordialmente entendido como um gosto de necessidade. Ainda que todos comam, os pratos das camadas populares estariam mais recheados com quantidade de alimentos, se houver essa possibilidade, e de tipos mais nutritivos, em oposição ao gosto de luxo burguês, definido pela liberdade conferida pela distância da necessidade. Ora, como pensar perfumes, um tipo de produto que parece ferir a lógica da necessidade por si só?

A afirmação "uso porque gosto" parece distanciar o consumo do produto de motivações mais imediatistas, como obtenção de favores, ao mesmo tempo em que não traz vínculo com uma possível tentativa de aproximação com estratos mais abastados, o que seria mais típico, de acordo com o jargão bourdiano, das camadas pretensiosas, ou seja, as camadas intermediárias. Por outro lado, a afirmação contém a indicação de que o consumo de perfumes seria uma finalidade em si mesma, o que aproximaria de uma lógica do gosto de luxo. No entanto, pelas entrevistas qualitativas, não se trataria de um gosto ligado à liberdade. Usar perfume "é básico", para não feder e para não ficar "cheirando a nada". Ao mesmo tempo que o uso do perfume não seria remissível a um objetivo imediatista, ele comparece como constitutivo do reconhecimento de si por parte de seu usuário. Não usar perfume tem duas consequências: cheirar a nada ou feder. Apesar da importância do recurso ao perfume como mecanismo para não feder ser fundamental à interpretação que se seguirá aqui, chama a atenção a compreensão de que não estar artificialmente odorizado significa cheirar a nada. Como chave interpretativa, me utilizo da 
personagem Grenouille - do livro de Patrick Süskind, O Perfume, história de um assassino (2010)[1985], adaptado para o cinema em 2006 e para série televisiva em 2018 - pois ele, de acordo com a narrativa, era desprovido de odores pessoais, característica que parece definidora de sua relação com as pessoas, com os cheiros e com o seu percurso na trama. Grenouille, por não ter cheiro, não tinha existência social, era insignificante e aberrante. O que ele desejava? Ser amado, existir. Para isso, ele busca criar o melhor perfume existente, que, contraditoriamente, viria do cheiro de mulheres, mas mulheres especiais, virgens portadoras de diferentes tipos de beleza que forneciam a essência para as notas aromáticas que comporiam os acordes de seu perfume, que levaria da lascívia ao amor divino. Cheirar é inescapável. Podemos transformar os odores que portamos a partir da adição de substâncias, mas não podemos não ter cheiros, ainda que nossa atenção, na hierarquização sócio-histórica dos sentidos, tenha levado à prevalência da visão e à diminuição de nossa reflexiva percepção dos odores à nossa volta. Arriscamos a perguntar: $\mathrm{O}$ que poderia levar a que cheiros externos, artificiais, fossem compreendidos como constitutivos de nós? Se assim for, estaríamos numa ordem de relação mais profunda de vínculo afetivo com um tipo de produto que teria papel de peso na definição das auto(estimas) e para as quais o debate a respeito do gosto a partir da distinção pode ter alcance limitado. Por outro lado, em que medida as entrevistas, mesmo em profundidade, poderiam descortinar processos naturalizados na forma do gosto pessoal? O gosto atual é uma sobrevivência do passado como memória prática, não-reflexiva. A socialização infantil, com recurso diário à perfumação, ainda que não explicitada em suas motivações, leva à constituição de um habitus ligado ao gosto pelo perfumar-se, ao mesmo tempo em que a uma hierarquização socialmente construída da relação entre odores, gêneros, gerações e ocasiões para uso. Fazendo parte de um gosto naturalizado e reforçado a partir de rituais diários domésticos, mas coletivamente exercitado, o recurso à perfumação simplesmente se mantém como inquestionável. Mesmo quando certas motivações para a perfumação infantil são explicitadas em teor de necessidade (para proteção contra "mau-olhado"), os usos parecem crescentemente se distanciar de sua necessidade inicial, pela fala dos entrevistados, e ganhar autonomia como finalidade em si. Enquanto resultado de um processo sócio-histórico, entendemos sociologicamente que a construção dos gostos, inclusive por perfumação pessoal, apesar do esquecimento social de sua história, é compreensível e, em função disso, buscaremos interpretá-lo levando em consideração o processo de constituição do Brasil, que certamente foi definidor na divisão que se operou no país entre regiões consumidoras de perfumes (Norte e Nordeste) e regiões produtoras (Sudeste e Sul), uma vez que os maiores gigantes da comercialização nacional de fragrâncias são o Boticário (Curitiba-PR) e a Natura (São Paulo-SP), que ampliaram, ambas, sua atuação nas regiões Norte e Nordeste após 2010 . 
De acordo com a Pesquisa de Percepção do Setor, estudo qualitativo elaborado pelo Instituto FSB Pesquisa para a ABIHPEC, entidade privada que representa 94\% do setor de Higiene Pessoal, Perfumaria e Cosméticos (HPPC), com cerca de 400 associados - " $95 \%$ dos entrevistados [em São Paulo, Porto Alegre e Salvador] entendem os produtos de HPPC como essenciais e indispensáveis para os cuidados básicos com a saúde, bem-estar e qualidade de vida. [...] Bem-estar é uma consequência da sensação de higiene, e não da vaidade" (ABIHPEC, 2018b, n.p.). Tais informações levaram a Associação, enquanto entidade orientadora das condutas empresariais no setor de HPPC e que gerencia e negocia as relações entre empresários e poder público, a estabelecer a essencialidade como pilar que deverá estruturar as atuações e investimentos do setor no biênio 2019-2020. Um desses passos se dirige às negociações para redução dos impostos cobrados ao setor e cujo aumento no contexto de crise foi entendido como fator que levou a uma maior retração das vendas nos últimos anos: "Apesar de serem produtos essenciais, muita gente acha equivocadamente, que o setor de HPPC é de produtos chamados supérfluos. Consequentemente, somos o segundo setor mais tributado da economia, atrás apenas do segmento de cigarros", conforme Daniel Lacasa (ABIHPEC, 2018a).

No entanto, os produtos mais essenciais destacados pela investigação do Instituto FSB Pesquisa seriam: absorvente higiênico, sabonete, escova dental, creme dental, fraldas descartáveis (ABIHPEC, 2018a). A partir de nossa pesquisa, compreendemos que parcela significativa de nordestinos pode entender que perfumes para uso pessoal fazem parte do rol dos produtos essenciais do setor. É nessa direção que esta investigação segue.

\section{Os cheiros e o Brasil em perspectiva histórica}

Compreender a conformação da disposição para o consumo de perfumes como comportamento cotidiano pouco dispensável demanda a consideração do modo como se deu o ingresso e desenvolvimento da perfumação industrial no Brasil, enquanto continuação das relações dos habitantes do país com os cheiros de modo geral. Em outras palavras, cabe compreender o processo de autonomização do perfume como produto cultural e capitalista em função das redes societais que se conformaram em diferentes modelagens neste vasto território. O marco primordial da investigação é, seguramente, a vinda da Corte Portuguesa para o Brasil, em princípios do século XIX, por suas consequências comerciais e sociais. Este é o momento do ingresso dos perfumes enquanto produto capitalista racionalizado no país, o que abriu espaço à posterior produção local, na segunda metade de século, nas boticas. Até esse momento, os habitantes social e economicamente mais privilegiados eram obrigados a se contentar com o pouco que vinha da Metrópole. Contudo, conforme afirma 
Aschcar (2001), após a Independência, em 1822, o Brasil rapidamente passou a consumir

[...] perfumes com incrível avidez. Registros da época mostram que em 1867 durante o reinado de Pedro II, sucessor do pai - o Brasil, por estranho que pareça, figurava entre os maiores importadores de perfumes franceses. Batido apenas pela Inglaterra, o Brasil importava 252 mil quilos - medida que consta da lista publicada em Le Livre des Parfums, livro editado em Paris em 1870 - enquanto Portugal não chegava a 19 mil. No entanto, a indústria de higiene e perfumaria local só começaria a ter alguma expressão cerca de vinte anos depois (ASCHCAR, 2001, p.107).

Ou seja, a disposição à odorização do corpo já estava constituída e ganhou impulso a partir do momento em que as disposições encontraram um produto correspondente que as satisfez. O estabelecimento da Corte no Brasil em 1808 não teria sido, portanto, o fator causador da disposição para perfumação pessoal, e sim o gatilho propiciador da efetivação das condições de realização da prática da perfumação a partir de fragrâncias criadas para o comércio com fins de embelezamento. A chegada dos perfumes, mais maciçamente, no território nacional oportunizava o contato com novos e diferentes cheiros, oriundos do desenvolvimento de uma indústria química ainda nascente que rumaria na direção da criação de odores abstratos, inexistentes na natureza, no mesmo século XIX. De qualquer modo, o específico percurso europeu de autonomização funcional, articulado à ascensão burguesa e protestante, levava a que o perfume ganhasse o específico recorte estético, mais vinculado ao belo e à sedução, do que às suas funções religiosas e terapêuticas. O perfume que chega ao Brasil no XIX já era um produto comercial criado para ser usado nos salões e marcava distinção de pertencimento a determinada classe. $\mathrm{Na}$ França de século XVIII, por exemplo, o aristocrata se esmerava em usar um perfume por dia. Ao mesmo tempo em que as ruas parisienses eram conhecidas por seu mau odor, a França se notabiliza por sua corte perfumada (FEYDEAU, 2007).

Na Europa, a saída dos perfumes das boticas para as lojas de cosméticos se deu ainda no século XIX. Quando a comunidade científica se volta à ação dos micróbios, os odores passam a ser compreendidos apenas como sintomas de pouca importância, e os perfumes são crescentemente associados a frivolidades, consequência da ascensão burguesa e de sua desconfiança em relação aos cheiros artificiais (CLASSEN; HOWES; SYNNOTT, 1996). Ainda assim, o século XIX será o período da disseminação do perfume, enquanto produto comercial, para diferentes partes do mundo (CLASSEN; HOWES; SYNNOTT, 1996, REINARZ, 2014). Em suma, os perfumes, na Europa, estavam sendo distanciados dos âmbitos da saúde e das concepções mágico-religiosas e sendo afirmados especificamente em 
seu caráter cosmético-estético, e a regulação moral burguesa começava a direcionar o gosto para os delicados florais, em detrimento dos lascivos perfumes de base animal (PERROT, 1996). No entanto, o Brasil, onde os frascos de perfume aportam no século XIX, havia trilhado um percurso bastante singular em comparação ao processo de secularização europeu.

O Brasil colonial foi espaço de encontros variados entre diferentes povos postos em relação. Mesmo os europeus que habitavam as terras brasileiras desde o XVI puseram em ação nestas terras, costumes de características pré-modernas, fazendo-os se prolongarem até o XIX. Tais costumes e crenças, ligados à afirmação do sobrenatural e de sua atuação, bem como a uma experimentação sensualista do mundo, aproximava-os de crenças e práticas de outros povos que habitaram o Brasil - o catolicismo se manteve estável em Portugal, a despeito do avanço protestante, mais fortemente sentido em outros recantos europeus a partir do XVII, responsável, como resultado das tensões estabelecidas, pela assunção de práticas menos sensualistas e mais racionalistas pelo catolicismo. Tanto indígenas de variados povos como africanos de diferentes Nações e portugueses comungavam de um sistema de crenças que se assemelhava em alguns pontos e que, em suas interpenetrações, possibilitou a circulação de conhecimentos e práticas que, mesmo ressignificadas, sedimentaram o lugar de destaque de específicos cheiros nas rotinas da Colônia Portuguesa. Lugar inóspito, habitado por criaturas assustadoras e ameaçador - pela iminência da morte por inimigos, acidentes ou doenças - a disseminada crença na magia fazia com que as diferentes formas de feitiçaria fossem acionadas como recurso de primeira ordem na tentativa de controle do mundo. Enquanto partícipes de um tipo de interpretação de mundo muito pouco marcada pela diferenciação, os diferentes sentidos (tato, paladar, audição e olfação, para além da visão) detinham significativa relevância na experimentação de mundo e, portanto, nas variadas práticas. Acredito eu que a fina articulação entre magia, saúde e sedução são o elemento de força na definição da importância que os cheiros mantêm mesmo com os avanços da secularização e da presença e atuação do corpo profissional médico no Brasil a partir do XIX.

Os banhos temperados com ervas eram um costume de indígenas e africanos para proteger o corpo contra insetos, como ligação com o divino, proteção contra infortúnios ligados ao sobrenatural, identificação do pertencimento a um grupo, cura... Sua ação ampliada permitia interferir no corpo, no sobrenatural e nas relações sociais, uma vez que eram utilizados também para a transformação deliberada de comportamentos dos outros. Lembremos do grande comércio de afrodisíacos no Brasil Colônia - inclusive, no vídeo-documentário Vaidade, citado no início deste texto, a manipulação de essências aromáticas para criação de perfumes de finalidade afrodisíaca também se fez presente, do mesmo modo que a remissão à concepção do valor sacro dos aromas pela afirmação de que 
João Batista teria batizado Jesus com água temperada por ervas aromáticas. Seja na ação de passar óleos nos corpos ou de tomar banhos aromatizados ou ainda através das práticas de lavar o chão e/ou roupas com folhas, bem como de defumação dos ambientes e pessoas, os cheiros compunham as dinâmicas cotidianas coloniais como condição de sobrevivência.

No caso dos portugueses, apesar da distância social para com indígenas e africanos, viver na Colônia, longe dos cuidados médicos, por si só contribuía para o recurso aos chamados feiticeiros. Para além disso, mesmo Portugal teve dificuldade em se afastar da crença em poderes mágicos para a cura do corpo. É o que justificaria a tardia ação da Inquisição na Metrópole e Colônia (séculos XVI a XIX), quando ela diminuía sua atuação em outros territórios. Inicialmente, a Inquisição buscava coibir a ação mágica demoníaca, reafirmando, assim, a possibilidade de atuação no mundo via magia, o que apenas posteriormente cederá lugar às afirmações de charlatanismo, negando a existência da possibilidade mágica (WALKER, 2013). No que se refere ao Brasil, os negros eram entendidos como os melhores feiticeiros. Ademais, a presença de escravos nos espaços domésticos facilitava as trocas. No desespero da iminência da morte ou do medo, o recurso à feitiçaria parece ter sido uma constante. E tal feitiçaria congregava comumente contribuições dos diferentes povos que se mantiveram em redes de interdependência, a objetos e práticas indígenas e africanas, foi comum a associação a menções e rezas a santos católicos (SOUZA, 1999). Havia ainda a crença nos miasmas, isto é, na transmissão de doenças através do ar e que teria no uso de bons cheiros a recobrir o ambiente e o corpo a melhor atitude preventiva (SANT'ANNA, 2011).

Deste modo, mesmo na segunda metade do século XIX, as práticas de cura e de higiene pessoal e doméstica continuavam presas às crenças no sobrenatural $\mathrm{e}$ no poder dos cheiros. Igualmente as crianças, em especial as recém-nascidas, eram protegidas através da defumação de seus pequenos corpos.

Assim, o secularizado perfume que chega ao Brasil serve ainda aos usos pouco diferenciados dos aromáticos, no modo como os seus habitantes faziam dele uso, a despeito das pressões, crescentemente intensas, no sentido de construir e pôr em prática um projeto civilizador para a ex-Colônia. De qualquer modo, o produto começava a ser simbolicamente associado a gente civilizada, o que significava segmentar e hierarquizar basicamente dois tipos humanos: os civilizados (usuários de certos perfumes) e os não-civilizados. Como se pode observar no fragmento do texto publicitário dedicado à Água de Florida de Murray e Lanman e ao Célebre Tônico Oriental de Lanmam e Kemp, publicado no Almanak Administrativo, Mercantil e Industrial do Rio de Janeiro, em 1846, mesmo com a referência à civilidade, permanece a menção aos poderes terapêuticos, como em diferentes outros anúncios ao longo do século. 


\section{O gosto e o cheiro: práticas de consumo e diferenças regionais no Brasil}

Estas ultimas perfumarias, garantidas, legitimas e verdadeiras, introduzidas em todo o mundo civilisado, têm invadido os toilletes mais distinctos e aristocraticos, e adquirido justamente alta reputação, tanto pela delicadeza de seu delicioso aroma, como pelos seus salutares effeitos.

Prescindindo, porém, dos numerosos e variados casos em que a sua applicação produz instataneos resultados therapeuticos, como os seus autores largamente enumerão e attestão, limitando-nos a apresenta-las, como uma urgente necessidade do toucador moderno, a todas as damas e cavalheiros que têm pretensões de possuir uma cutis clara, macia e delicada, e uma cabeleira vasta e formosa. rua das Violas, 13, esquina da rua da Candelária.

O discurso de necessidade do produto, acionado no anúncio, parece se referir à urgência de mudança na categoria de humano em pauta em direção ao distinto. $\mathrm{O}$ produto não se dirige aos civilizados, mas àqueles que o desejem ser. Em suma, a magia se mantém, mas é atualizada às novas condições.

Papel de destaque na tentativa de ressignificação dos aromáticos em conformidade com um projeto civilizador para o Brasil advirá dos médicos profissionais, após a abertura das Faculdades de Medicina na Bahia e no Rio de Janeiro, em 1836. Contrapondo-se aos usos de perfumações, no cotidiano doméstico e nos salões, os médicos advertirão igualmente contra o exercício do curar por parte de não-profissionais, a quem eles acusarão de charlatães. O modelo de civilização por eles pregado tem por referência a França, a Inglaterra e os Estados Unidos, mas, ao mesmo tempo, buscam na moralidade cristã o elemento de correção dos vícios decorrentes da civilização e para a construção de um modelo aperfeiçoado de civilização para o Brasil (CARDOZO, 1857). Um desses vícios, ao lado do haxixe, da coca, do álcool e do fumo seria o perfume, que, conforme Guarino Freire (1888), seria um corruptor da moral, por sua presença nos salões e poder de despertar desejos sexuais, mas também uma ameaça por provocar cefaléias, histeria e mesmo abortos e a morte, ameaçando a família e a formação dos cidadãos do futuro. O discurso burguês médico está em tensão com as sociabilidades aristocráticas trazidas pela Corte, de participação na cena pública através dos salões, bem como ao discurso eclesiástico de confinamento doméstico, apesar do apelo à moralidade cristã. Tais tensões evidenciam as acirradas disputas simbólicas que tomaram lugar em fins de século no exercício do poder de direcionar as condutas humanas mediante a instituição de agentes legítimos e legitimados de produção das violências simbólicas. Assim, igualmente caracteriza-se o modo como vai se dando o processo de autonomização no Brasil, que inicia quando, na Europa, está a se consolidar. Tal descompasso, obviamente, é decorrente das tentativas de acomodação entre processos colonizador/ descolonizador e projeto civilizador. 
Do mesmo modo, a abrangência de tais ações e debates, bem como o grau de sua repercussão, estiveram na dependência de dois outros fatores: os locais de presença desses médicos e da Corte, por um lado, e, por outro, o grau de maior/ menor dispersão dos agrupamentos indígenas e negros. Quanto maior a integração dos grupos, o que ocorreu mais facilmente em relação aos negros em ambiente agrícola do que pecuário e de mineração, em ambiente urbano do que rural, maior a sedimentação de determinados costumes, inclusive aqueles ligados à crença na magia dos cheiros. Para Édison Carneiro (2008), o isolamento regional somado ao maior ou menor adensamento populacional é fundamental para compreendermos a continuidade dos cultos jejes-nagôs na Bahia, onde há grande concentração de negros e mestiços, e a aceitação, por parte dos povos amazônicos, igualmente isolados mas de população rarefeita, dos cultos vindos do Maranhão. Do mesmo modo, quanto maior a presença de um estilo de vida aos moldes aristocráticos, assumidos como comportamentos legítimos, maior a pressão civilizadora. Quanto maior a presença de médicos e bacharéis em Direito e a pressão pela constituição da República, maior ênfase na direção do desencantamento, intelectualização e racionalização no Brasil uma vez que esses foram os primeiros cursos em faculdades brasileiras.

Com a instalação da Corte no Rio de Janeiro, tornada capital do Brasil, esta cidade passa a ser o centro irradiador das condutas civilizadas, do progresso e lugar dos maciços investimentos. O chamado Sudeste do Brasil se direcionará à busca pela modernização e progresso, conformando a base para sua precoce industrialização, em comparação com o restante do país. De qualquer modo, se Norte e Nordeste perdem espaço e brilho com a descolonização, tornando-se mais empobrecidas e abrigo dos índios e negros do país, as regiões Sudeste e Sul, enriquecidas e passando a conduzir os destinos da nova Nação, avançaram na direção da industrialização e investirão na imigração de europeus para branqueamento de sua população e para conformar a base da construção de seu caminho para o progresso, tornando as demais regiões seus anversos: imagens de atraso, relegadas ao isolamento. Ao mesmo tempo, a vinda de imigrantes advindos de uma Europa mais avançada na secularização, certamente deve ter servido igualmente de contribuição à constituição de um habitus singular (mais esteticamente significado) no que se refere ao gosto por perfume.

De acordo com o relatório do Euromonitor (ABIHPEC; SEBRAE, 2018), nos Estados Unidos, país que hoje ocupa o primeiro lugar no ranking de consumo de perfumes para uso pessoal, as pessoas, apesar de sua condição financeira mais favorável, fazem uso eventual das fragrâncias, em conformidade com a concepção de liberdade de uso, a que referimos com base em Bourdieu (2007). A relação com o perfume, no Sudeste e Sul, parece ir em direção similar, diferente do que ocorre com o Norte e Nordeste. No caso destas regiões, marcadas por maior integração de negros e de índios, bem como de negros junto a índios, ao mesmo tempo em que 
isoladas quando do avanço industrial do Sudeste-Sul, vivendo nostalgicamente seu passado colonial e sem recursos para investimento nas levas migratórias europeias, viveram o terreno fértil necessário à manutenção relativa de maior indiferenciação por mais tempo, em compasso com um desenvolvimento industrial bastante tímido e tardio. E talvez, contraditoriamente, a especificidade dessa autonomização tenha sido determinante para o lugar privilegiado que os perfumes comerciais virão a ocupar no cotidiano nordestino e nortista ao longo dos séculos XX e XXI.

No entanto, existe um elemento adicional a considerar no que toca à particular participação das camadas socioeconômicas menos favorecidas no consumo de perfumes no Brasil: o preconceito racial, uma vez que essas camadas são compostas primordialmente por negros. Como nos lembram Elias e Scotson (2000), os processos de estigmatização se dirigem fundamentalmente às características mais aparentes do outro como sinal indelével e visível de sua inferioridade. Por excelência, tais processos seguem na afirmação da condição de menor grau de humanidade (os subumanos), quando não de animalidade desses grupos/povos, o que ganha maior efetividade com a internalização do preconceito por parte daqueles que são dele vítimas. As diferenças nos cheiros entre grupos e povos há séculos foi tomado como marcador de distinções. O suor do trabalhador, bem como seu suposto gosto por perfumes fortes, foram tomados como evidência de inferioridade na Europa, do mesmo modo que a afirmação do caráter primitivo dos povos africanos, por aquilo que foi entendido como uso acentuado do olfato para localização espacial determinando sua condição de bons caçadores. No caso dos negros, chegou-se a criar uma teoria de associação da cor da pele com sua suposta inferioridade e mau odor a partir da ideia de que o preto estaria ligado à putrefação (REINARZ, 2014). No Brasil, que promoveu a escravização de negros, a afirmação de seu mau cheiro (bodum, fedor de bode), hoje também denominado CC (cheiro da cor), também se fez presente para inferiorização e diminuição da autoestima de um povo que, diferente dos brancos portugueses, prezava os banhos, mas era obrigado aos árduos trabalhos em terra tropical, sem direito aos devidos cuidados de si. O afirmado fedor do corpo torna o arbitrário social repulsa física e faz confundir fedor, sujidade corporal e sujidade moral, uma vez que a inferiorização ajuda a definir a hiper-sexualização do negro, tornado mais próximo do primitivo e, logo, do animal (GROSSI, 2003). Do mesmo modo como o negro tinha nos sapatos um objeto de desejo por simbolizar liberdade (apenas os libertos podiam fazer uso de calçados), em que medida, para além do caráter mágico-curativo/protetivo-erótico dos cheiros, os perfumes não se tornaram objeto de desejo por servir de instrumento para contraposição à violência simbólica da afirmação do mau cheiro natural do corpo negro? Como visto anteriormente, ao perfume foi atribuído o poder de identificar o civilizado e, acima de tudo, transformar em civilizado. Assim, o perfume poderia ser tomado igualmente como instrumento de elevação das estimas e necessário, 
em termos de uso cotidiano, em especial considerando grupos que já praticavam a perfumação pessoal. No que toca às entrevistas em profundidade realizadas em Cachoeira-BA, cidade negra por excelência, compreende-se que, junto à afirmação de que não usar perfume significaria "cheirar a nada", figure a afirmação de que não usá-lo significa feder.

Para aprofundar as discussões, tomaremos o caso de um perfume em particular, cujo aroma foi entendido por Aschcar (2001) como o cheiro do Brasil até os anos 1980: a lavanda.

\section{Cheiro de Alfazema/Lavanda}

Lavanda e alfazema ${ }^{1}$ são as denominações latina e árabe, respectivamente, para a Lavandula, planta mediterrânea, com uma variedade de subespécies ${ }^{2}$, que, desde a chamada Antiguidade, conecta povos da Europa, do Norte da África e oeste da Índia a partir das intensas trocas estabelecidas pela Arabia Felix em torno das especiarias, uma variedade de produtos com características aromáticas (BERNSTEIN, 2009, CAMARGO, 2014). A lavanda, cujo significado advém etimologicamente do verbo lavar, era amplamente utilizada para perfumar, lavar roupas e casas (por seu poder germicida) e como remédio. Segundo Lis-Balchin (2003), os gregos e romanos se referiam à lavanda como nardo, o que permitiria afirmar sua presença nos textos bíblicos (Jo 12, 1-8; Mc 14, 3-9). Na verdade, há inúmeras referências a cheiros na Bíblia, no Antigo e no Novo Testamento, seja a representação do Éden como um vasto jardim, as oferendas odoríferas a Deus (holocaustos e incensamentos), a presença de Deus como nuvem (odorífera), os presentes dos Reis Magos a Jesus, o presente de Maria a Jesus em Betânia, o embalsamamento de Jesus, dentre outras. A presença do divino seria também marcada pelos odores, o que permitia identificar pessoas santas: o chamado cheiro de santidade. As Igrejas católicas cheiravam a incenso para marcar a presença de Deus, ao mesmo tempo em que eram lavadas com água de cheiro, que tinha na lavanda um de seus principais ingredientes. Como lembra Câmara Cascudo 1998, p.718), "não era apenas o africano que banhava seus fetiches com azeite mas também o romano o fazia com óleos sagrados". E lavar o chão com água-de-cheiro parece ter sido um costume comum de europeus e africanos. De qualquer modo, a Europa usou a lavanda por séculos, tendo a Igreja Católica mantido esse uso durante o período medieval e, mesmo após, a lavanda se manteve presente para fins religiosos, medicamentosos (ela foi usada para aplacar a peste, do mesmo modo que para aliviar as enxaquecas da Rainha Elisabeth) ou simplesmente para perfumar o

\footnotetext{
Segundo Câmara Cascudo (1998) e Chernoviz (1890), a alfazema é um tipo de Lavandula.
}

2 Lavandula vera, Lavandula officinalis, dentre outras. 
corpo de reis, rainhas e seu séquito de nobres. Foi na Era Vitoriana que, segundo Lis-Balchin (2003), a lavanda se tornou um dos odores mais populares, junto com a rosa e a violeta, sendo usada, inclusive, para lavar os dedos dos convidados durante os banquetes festivos (STRONG, 2004). Lembra ainda Lis-Balchin (2003) que a Água de Colônia tinha o óleo de lavanda como base. A França e a Inglaterra foram as principais responsáveis pela ulterior comercialização da lavanda para diferentes recantos do mundo.

No caso do Brasil, devemos ter em conta a presença e peso da Igreja Católica durante o período colonial e a grande possibilidade de ter sido a Igreja a começar a disseminar o uso da lavanda junto aos habitantes locais. Isso porque, apesar de africanos conhecerem a alfazema (ao menos, os africanos de algumas regiões do continente), a planta é de difícil aclimatação no Brasil. "As plantas medicinais, particularmente as especiarias, tiveram lugar importante nas trocas culturais entre o Oriente árabe e o Ocidente cristão, nas regiões de ocupação árabe no sul da Itália, Espanha e Portugal" (CAMARGO, 2014, p. 95). O Norte do Brasil pode ter sido seu porto de entrada. Lembrando que além do tráfico de pessoas, o processo colonizador foi marcado pelo tráfico de animais e de plantas, o que se intensificou a partir da criação dos jardins botânicos, o que em Portugal ocorreu no século XVIII. De qualquer modo, os seus sentidos religioso-medicamentoso e possível uso prévio por parte de portugueses e africanos, para além do impulso ao comércio de lavandas por parte tanto de Inglaterra como França, nos ajudam a compreender como a planta e os perfumes à base de alfazema/lavanda ganharam tamanho espaço no Brasil. No entanto, o elemento adicional da dificuldade de aclimatação da planta nestas terras, provavelmente, foi fator adicional para a curiosa utilização do perfume de alfazema industrializado em rituais religiosos.

ALFAZEMA. Lavandula vera, De Candolle. Planta da família das Labiadas, cultivada nos jardins [...]. Tem talo esbranquiçado, folhas azuladas, dispostas em espigas terminaes; cheiro aromatico. Estimulante. Emprega-se principalmente para os banhos aromaticos; na dose de 500 a 1,000 gramas da planta para um banho d'agua quente. Contém um oleo essencial que serve para a preparação da agua de Colonia. Muitas pessoas costumam queimar alfazema nos quartos dos doentes, com o que não fazem senão encobrir incompletamente o máo cheiro, mas não destroem miasmas; é melhor abrir as portas e janellas para renovar o ar, ou espalhar licor de Labarraque, que ataca e destroe as emanações nocivas à saúde $[\ldots]$.

Colhida em plena florescencia, reunida em pequenos mólhos que se fazem seccar à sombra, a alfazema espalha, nos armarios que contém roupa ou vestidos, um cheiro agradavel, tendo além d'isto a propriedade de afugentar os bichos que atacam sobretudo as fazendas de lã. (CHERNOVIZ, 1890, p.99). 
A afirmação de Aschcar (2001) de que a alfazema/lavanda foi o cheiro do Brasil ao longo do XX se sustenta a partir da visada à história dos perfumes produzidos no país e que obtiveram boas respostas em consumo, a exemplo de Acqua Fresca, Lavanda Pop, Thaty, Giovanna Baby, Rastro (primeiro perfume de luxo produzido no Brasil), Alfazema Suissa, mas, sem dúvidas o grande destaque é a Seiva de Alfazema, inicialmente produzido pela Phebo.

Ao ir a um supermercado em Salvador-BA e perceber, quando parada em um semáforo, que estava na Rua da Alfazema, a curiosidade me incitou a observar o que era vendido na sessão de perfumaria. Com pouco espanto, contabilizei que, dos 23 tipos de perfumes comercializados para mulheres e crianças no referido centro comercial para uma clientela de menor renda, 12 apontavam explicitamente a lavanda ou alfazema como nota de sua composição. O carro-chefe dos perfumes expostos, pela quantidade de unidades à disposição da clientela, era a Seiva de Alfazema (118 ml), cuja produção no Brasil, enquanto perfume, inicia-se em 1941 pela Phebo. Ainda sem grande surpresa, ao entrar em uma farmácia na cidade de Cachoeira-BA, notei que havia quatro variedades da seiva de alfazema à disposição do cliente, três das quais de produção baiana. Podemos também observar a presença do perfume industrial Seiva de Alfazema como presente recorrente à orixá Iemanjá, na festa dedicada a ela no dia 02 de fevereiro, nas mãos dos homens que saem no Afoxé Filhos de Ghandi, no carnaval soteropolitano, nas mãos das Senhoras do Cajado nas festividades da Irmandade da Boa Morte em Cachoeira-BA, e como ingrediente da água de cheiro nos potes de cerâmica carregados pelas baianas para lavar a cabeça dos devotos na Lavagem do Bonfim, na segunda quinta-feira do ano em Salvador-BA. Se Denise Bernuzzi Sant'Anna (2011, p.285) nos fala de como era comum, em fins do século XIX brasileiro, o odor "da alfazema queimada, proveniente dos braseiros feitos de barro ou metal", numa fala próxima a Gilberto Freyre (2002, p.148) ao assinalar que "o brasileiro da época nascia com a casa toda cheirando a alfazema", considero ser possível afirmar que ainda sinto, e sinto mesmo, cheiro de alfazema no ar.

O Pará foi o berço da Seiva de Alfazema, criada pelos primos portugueses Antonio e Mario Santiago em princípios do anos 1940 e que se tornou o perfume do brasileiro por muitas décadas. Os primos iniciaram seu percurso quando adquiriram a Perfumaria Luzitana, em Belém-PA, posteriormente batizada de Phebo.

O grande salto, no entanto, veio com a Lavanda Phebo (1943), posteriormente renomeada como Seiva de Alfazema. Alçada ao posto de líder na perfumaria nacional, mantendo-se nessa posição durante muitos anos, a lavanda inspirada nos Alpes Suíços agradou em cheio, com notas de flor de alfazema garantindolhe um frescor predominante. Produzida inicialmente na fábrica de Belém e comercializada em frascos de meio litro, essa produção de ares artesanais 


\section{O gosto e o cheiro: práticas de consumo e diferenças regionais no Brasil}

respondeu à crescente demanda do mercado. Não foi preciso criar conceitos ou imagens para que os consumidores se identificassem com ela. Era, simplesmente, um fenômeno! E por muito tempo: a Phebo chegou a vender 8 milhões de unidades de colônia em 1986. (ASCHCAR, 2001, p.112).

Criada, portanto, ainda na primeira metade do XX, a Seiva de Alfazema conecta o século XIX ao XXI, uma vez que permanece sendo comercializada nos dias atuais. O seu imenso sucesso ao longo de décadas revela o quanto este produto funciona como uma expressão e sobrevivência de um século XIX, cujas marcas ainda se faziam sentir nos princípios do XX, ao mesmo tempo que traz os elementos fundamentais do novo século que garantirão sua permanência ao longo do XX e com desdobramentos no XXI. A sua ampla aceitação comercial evidencia o seu caráter expressivo, enquanto produto cultural-simbólico, ao sintetizar em frasco de perfume uma miríade de significados caros remetidos aos cheiros pelos habitantes do Brasil durante vasto período. Na cidade de Cachoeira-BA, como parte da pesquisa que fundamenta este artigo, foi realizado um teste aromático. Foram postos em frascos padronizados e não-identificados cinco perfumes de marcas distintas, masculinos e femininos (segundo a classificação comercial) e de diferentes famílias olfativas. Dentre esses perfumes, em sua maioria nacionais, figurou a Seiva de Alfazema. A intenção do teste foi aferir sobre expertise e associações simbólicas remetidas aos cheiros sentidos. No caso da fragrância em pauta, os entrevistados associaram a aroma de bebê, bem-estar, candomblé, detergente, dormir, feitiçaria, infantil, pósbanho-relaxar, sair, espantar mosquitos. Em outras palavras, os respondentes de século XXI, a partir do cheiro sentido, resgataram usos atuais, mas igualmente remissíveis ao XIX. Como afirma Bourdieu (2009), as objetivações acionam sentidos nelas depositados. Os cheiros são fortes gatilhos de memória. Assim, podemos afirmar que agem a memória. Enquanto sobrevivência (WARBURG, 2010), o objeto perfume mantém uma relação de contiguidade com o passado e o atualiza em novas formas que respondem igualmente ao contexto de produção já desvelando um porvir, mesmo que apenas insinuado. Esta seria a fórmula para a compreensão e identificação dos grandes artistas, segundo Aby Warburg (2010), historiador hamburguês do século XIX, mas talvez pudéssemos usar a sua chave interpretativa para pensar até mesmo um produto comercial que consegue se manter com grande aceitação popular no Nordeste há quase 80 anos. Os usos atuais do perfume Seiva de Alfazema continuam sendo, conforme a pesquisa, a perfumação dos corpos, roupas e objetos de recém-nascidos, pelo odor leve e fresco e para a proteção física e espiritual; a proteção e purificação dos adultos e de suas casas; o uso religioso, no candomblé e no catolicismo; relaxamento, sendo usado por algumas pessoas antes de dormir (inclusive é bastante comum seu uso na aromaterapia); contra traças nas roupas; pelo frescor e sensação de bem-estar que proporciona. Além disso, 
observamos um fator geracional. Os anos 1980 foram marcados ainda por presença maciça da Seiva de Alfazema nos lares, além das outras lavandas comercializadas na época - o primeiro perfume lançado pela Boticário, em 1979, foi uma lavanda, a Acqua Fresca, e, em 1985, lança outra lavanda de sucesso, Thaty. A diversificação das prateleiras de perfumes dos brasileiros começa a ocorrer a partir dos anos 1990 com a abertura comercial. No entanto, a geração nascida no período ainda mantém forte relação com o uso de lavandas; as gerações mais jovens, por sua vez, as têm, para além das possíveis questões religiosas, como a porta de entrada para o uso de fragrâncias e, portanto, para o gosto por usá-las.

\section{Considerações Finais}

Ainda que hierarquizações sejam percebidas, separando perfumes nacionais e estrangeiros, baratos e caros, da moda e de nicho, massivos ou personalizados, escolhidos e usados em função de classes, de habitus que conjugam de modo específico capital econômico e capital cultural e, portanto, em conformidade com uma lógica da distinção e legitimação de determinados padrões de gosto, pudemos observar que a compreensão do destacado gosto brasileiro por perfumes, em algumas de suas clivagens regionais, passa por uma compreensão que ultrapassa o vetor da distinção, em especial quando tomamos uma essência aromática, a lavanda, que comparecia ligando e articulando as diferenças culturais e econômicas. Do mesmo modo como a Seiva de Alfazema se dissemina como produto popular, o primeiro perfume de luxo criado no Brasil, Rastro (1965), também teve a lavanda como nota aromática definidora.

Por outro lado, o gosto pelo uso do perfume se mostra mais acentuado nas camadas populares, mas em conformidade com uma lógica específica que torna o perfume um bem de necessidade, na medida em que, por seu uso desde tenra idade e contínuo, bem como por sua miríade de significados associados, em especial de potencial mágico: apenas sou na medida em que estou perfumado. Neste sentido, por mais que seja possível perceber o acionamento da associação eventual entre perfume e falseamento (concepção do artifício), sobressai o entendimento de que sou com o perfume que porto porque o cheiro, mesmo artificializado, faz parte de mim. Para além disso, o gosto por alfazema apenas se torna inteligível a partir da correlação entre produto comercial diferenciado e a pouca diferenciação ainda reinante. Ou seja, pela presença de um produto autonomizado em seu sentido num contexto ainda de fraca autonomização, o que fez com os usuários do perfume transferissem para ele o peso de uma articulação de significados que, a rigor, recobriria indiferenciadamente variadas esferas de sentido sem que esses sentidos estivessem sequer claramente hierarquizados entre si, o que se acentua no caso da alfazema devido a seus 
múltiplos usos ao longo da história, desde a chamada Antiguidade. Por outro lado, a dificuldade de aclimatação da alfazema em solo brasileiro pode ter contribuído para essa transferência de significados, que envolvia o mágico, para perfumes produzidos longe (perdendo-se o contato com o fazer) e em escala ampla.

Assim, o gosto do nordestino e do nortista por perfumes, diferente do que ocorre no Sudeste e no Sul, regiões estas com maiores condições, inclusive econômicas, para um maior investimento em consumo do produto, se destaca na medida em que seu percurso de autonomização foi se dando mais lentamente por condições sócio-históricas, mas em simultaneidade aos francos avanços vividos no país na disseminação de um série de produtos industriais ligados à chamada vida moderna. Tornado necessidade, o produto perfume compõe as rotinas. Esquecido em seu processo de penetração no cotidiano brasileiro, mantém a sua presença como finalidade em si, recurso de importância na construção das (auto)estimas, e como objeto mágico.

\section{THE TASTE AND THE SCENT: CONSUMPTION PRACTICES AND REGIONAL DIFFERENCES IN BRAZIL}

ABSTRACT: The purpose of this article is to understand the Brazilians'taste for perfume. Brazil is the second largest consumer of perfumes in the world. The most consumed products are the national and mass-produced ones. The largest consumers are people of Classes $C, D$ and $E$ from the north and northeast regions in the country, who according to IBGE (2010), spend more on perfumes monthly than on food or education. The starting point is the debate about the supposed superfluous character of perfumes, in the light of the socio-historical peculiarity of Brazil. From this point, we seek to understand this taste in relation to what was considered by the researcher Aschcar as the scent of Brazil in the twentieth century-lavender-from one of its outstanding products in the national history of perfumery: the Seiva de Alfazema, created by Phebo.

KEYWORDS: Taste. Scents. Consumption. Perfumes. Brazil.

\section{EL GUSTO Y EL OLOR: PRÁCTICAS DE CONSUMO Y DIFERENCIAS REGIONALES EN BRASIL}

RESUMEN: El objetivo de este artículo es comprender el gusto del brasileño por el perfume. Brasil es el segundo mayor consumidor mundial de perfumes. Los productos más consumidos son los nacionales y masivos. Los mayores consumidores 
son personas de las Clases $C$, D y E de las regiones Norte y Nordeste, que, según datos del IBGE (2010), gastan familiarmente por mes más con perfumes que con arroz o educación. El punto de partida es el debate sobre el supuesto carácter superfluo de los perfumes, a la luz de la particularidad socio-histórico de Brasil. Dentro de esa perspectiva buscamos comprender ese gusto a partir de la relación de lo que fue considerado por la investigadora Aschcar como el olor de Brasil en el siglo XX, la lavanda, por medio de uno de sus productos de destacado en la historia nacional de la perfumería: la Seiva de Alfazema creada por la Phebo.

PALABRAS CLAVE: Gusto. Olores. El consumo. Perfume. Brasil.

\section{REFERÊNCIAS}

ABIHPEC. Anuário 2018. 2018a. Disponível em: <abihpec.org.br/anuario-2018-flip/mobile/ index.html\#p=1>. Acessado em: 12 fev. 2019.

. Panorama do Setor de Higiene Pessoal, Perfumaria e Cosméticos: Resultados 2017. 2018b. Disponível em: <abihpec.org.br/publicacao/panorama-do-setor-2018>. Acessado em: 15 fev. 2019.

ABIHPEC, SEBRAE. Caderno de Tendências 2019-2020: Higiene Pessoal, Perfumaria e Cosméticos, 2018. Disponível em: <https://abihpec.org.br/publicacao/caderno-detendencias-2019-2020/>. Acessado em: 12 fev. 2019.

ALMANAK ADMINISTRATIVO, MERCANTIL E INDUSTRIAL DO RIO DE JANEIRO. Rio de Janeiro, 1846. Acervo da Biblioteca Nacional (Hemeroteca Digital).

ASCHCAR, Renata. Brasilessência: a cultura do perfume. São Paulo: Nova Cultural; Editora Best Seller, 2001.

BERNSTEIN, William J. Uma mudança extraordinária: como o comércio revolucionou o mundo. Rio de Janeiro: Elsevier, 2009.

BOURDIEU, Pierre. O senso prático. Petrópolis, RJ: Vozes, 2009.

Zouk, 2007.

A distinção: crítica social do julgamento. São Paulo: Edusp; Porto Alegre-RS:

BRASIL. INSTITUTO BRASILEIRO DE GEOGRAFIA E ESTATÍSTICA (IBGE).

Contas Regionais do Brasil 2010-2016. Disponível em: <ftp://ftp.ibge.gov.br/ContasRegionais/2016/xls/PIB_Otica_da_Renda.xls $>$. Acessado em: 12 fev. 2019. 
. INSTITUTO BRASILEIRO DE GEOGRAFIA E ESTATÍSTICA (IBGE). Pesquisa de Orçamentos Familiares 2008-2009: despesas, rendimentos e condições de vida. Rio de Janeiro: IBGE, 2010.

CAMARGO, Maria Thereza Lemos de Arruda. As plantas medicinais e o sagrado: a etnofarmacobotânica em uma revisão historiográfica da medicina popular no Brasil. São Paulo: Ícone, 2014.

CARDOZO, Cid Emiliano de Olinda. Influencia da civilisação sobre o desenvolvimento das afecções nervosas. Tese (Doutorado em Medicina) - Faculdade de Medicina da Bahia. Salvador: Typographia de Antonio Olavo da França Guerra, 1857.

CARNEIRO, Édison. Candomblés da Bahia. 9.ed. São Paulo: Editora WMF Martins Fontes, 2008. (Raízes).

CASCUDO, Câmara. Dicionário do folclore brasileiro. 9.ed. Rio de Janeiro: Ediouro publicações, 1998. (Coleção Terra Brasilis).

CHERNOVIZ, Pedro Luiz Napoleão. Diccionario de medicina popular e das sciencias accessórias para uso das familias. 6.ed. Paris: A. Roger \& F. Chernoviz, 1890. Disponível em: <www.brasiliana.usp.br/sites/default/files>. Acessado em: 15 ago. 2014.

CLASSEN, Constance; HOWES, David; SYNNOTT, Anthony. Aroma: a história cultural dos odores. Rio de Janeiro: Jorge Zahar Ed., 1996.

ELIAS, Norbert, SCOTSON, John. Os estabelecidos e os outsiders: sociologia das relações de poder a partir de uma pequena comunidade. Rio de janeiro: Jorge Zahar Ed., 2000.

FEYDEAU, Élisabeth de. Europe: Courtly Perfume and Country Perfume in the Eighteen Century. In: GRASSE, Marie-Christine (Ed.). Perfume, a global history: from the origins to today. Paris/Grasse: edited and published by Smogy Art Publisher, 2007.

FREIRE, Guarino Aloysio Ferreira. Qual o papel que desempenha a civilisação no movimento das molestias mentaes. Tese (Doutorado em Medicina) Faculdade de Medicina da Bahia. Salvador: Bahia Imprensa Popular, 1888.

FREYRE, Gilberto. Ordem e progresso. Rio de Janeiro: Nova Aguilar S.A., 2002 (Intérpretes do Brasil, v. III).

GROSSI, Gabriele. O luxo do lixo: uma etnografia doa catadores de lixo. Salvador, Ba: Universidade Católica do Salvador, 2003.

LIS-BACHIN, Maria. Lavender: the genus Lavandula. New York: CRC Press: Taylor \& Francis e-Library, 2003. 
NERY, Maria Salete de Souza. O Nordeste e o mercado nacional de fragrâncias: notas para um mapa da produção/consumo de perfumes no Brasil. Ciências Sociais Unisinos, v. 53, n. 1, 2017, p. 56-66. Disponível em: <http://revistas.unisinos.br/index.php/ciencias_sociais/ article/view/csu.2017.53.1.07>. Acessado em: 26 mai. 2019.

PERROT, Philipe. Fashioning the bourgeoisie: a history of clothing in the nineteenth century. Princeton, New Jersey: Princeton University Press, 1996.

REINARZ, Jonathan. Past Scents: historical perspectives on smell. Chicago: University of Illinois Press, 2014.

SANT'ANNA, Denize Bernuzzi de. Higiene e Higienismo entre o Império e a República. In: PRIORE, Mary Del, AMANTINO, Márcia (Orgs.). História do corpo no Brasil. São Paulo: Editora UNESP, 2011. p. 16-44.

SANTOMAURO, Antonio C. Investimentos seguem aumento da demanda e sua diversificação. QUÍMICA.com.br. Publicado em 14 de julho de 2011. Disponível em: $<$ http://www.quimica.com.br/pquimica/aromas-e-fragrancias-investimentos-seguemaumento-da-demanda-e-sua-diversificacao > . Acessado em: 01 jan. 2014.

SOUZA, Laura de Mello e. O Diabo e a Terra de Santa Cruz: feitiçaria e religiosodade popular no Brasil colonial. São Paulo: Companhia das letras, 1999.

STRONG, Roy. Banquete: uma história ilustrada da culinária, dos costumes e da fartura à mesa. Rio de Janeiro: Jorge Zahar Editor, 2004.

SÜSKIND, Patrick. O perfume: história de um assassino. 29.ed. Rio de Janeiro/São Paulo: Record, 2010.

VAIDADE. Documentário. Direção e roteiro: Fabiano Maciel. Produção Executiva: Leonardo Dourado e Sacha. Brasil: Jobi Filmes, Santa Clara, Telenews e Videografia, GNT. 1 DVD (54 min), NTSC, 2003.

WALKER, Timothy D. Médicos, medicina popular e Inquisição: a repressão das curas mágicas em Portugal durante o iluminismo. Rio de Janeiro; Lisboa: Editora Fiocruz; Imprensa de Ciências Sociais, 2013.

WARBURG, Aby. Histórias de fantasma para gente grande: escritos, esboços e conferências. São Paulo: Companhia das Letras, 2010. (História Social da Arte).

Recebido em 06/03/2019.

Aprovado em 06/04/2019. 